\title{
A Rare Case of Tuberculosis Cutis Colliquative
}

\author{
Shravya Rimmalapudi ${ }^{1}$, Amruta D. Morey ${ }^{2}$, Bhushan Madke ${ }^{3}$, Adarsh Lata Singh ${ }^{4}$, Sugat Jawade ${ }^{5}$ \\ 1, 2,3,4, 5 Department of Dermatology, Venereology and Leprosy, Jawaharlal Nehru Medical College, \\ Datta Meghe Institute of Medical Sciences, Wardha, Maharashtra, India.
}

\section{INTRODUCTION}

Tuberculosis is one of the oldest documented diseases known to mankind and has evolved along with humans for several million years. It is still a major burden globally despite the advancement in control measures and reduction in new cases ${ }^{1}$ Tuberculosis is a chronic granulomatous infectious disease. It is caused by Mycobacterium tuberculosis, an acid-fast bacillus with inhalation of airborne droplets being the route of spread.2,3 The organs most commonly affected include lungs, intestines, lymph nodes, skin, meninges, liver, oral cavity, kidneys and bones. ${ }^{1} \mathrm{About}$ $1.5 \%$ of tuberculous manifestations are cutaneous and accounts for $0.1-0.9 \%$ of total dermatological out patients in India. ${ }^{2}$ Scrofuloderma is a type of cutaneous tuberculosis (TB) which is a rare presentation in dermatological setting and is difficult to diagnose. It was earlier known as tuberculosis cutis colliquative develops as an extension of infection into the skin from an underlying focus, usually the lymph nodes and sometimes bone. We hereby present a rare case of scrofuloderma on the skin of the neck.

\section{PRESENTATION OF CASE}

A 65-year-old female presented to dermatology section with a single raised lesion over V-area of the neck since two months. It started as multiple, tiny, hard nodular lesions over lower neck which gradually softened and broke through skin surface discharging pus at few places. The lesion was associated with mild discomfort and tenderness. Patient reported that her elder son was a treated case of pulmonary tuberculosis ten years ago. On examination, there were multiple nodules coalescing to form a large well defined erythematous plaque with slight violaceous border of around $15 \times 7 \mathrm{~cm}$ extending symmetrically from below the earlobe on both the sides of the neck meeting at the front in a necklace pattern covering the $V$ area of neck with an ulcer at the centre of the plaque around $2 \times 3 \mathrm{~cm}$ in size with base covered with slough having irregular rolled up margins [Figure 1]. There were bilateral palpable non matted posterior cervical lymph nodes around $2-3 \mathrm{~cm}$ diameter.

Complete haemogram, chest radiograph and serum biochemistry were within normal reference range except mild anaemia. Tuberculin skin test was strongly positive reaction showing $20 \times 15 \mathrm{~mm}$ of induration. Cartridge based nucleic acid amplification test (CB-NAAT) from pus showed tubercle bacilli in low quantity.

Punch biopsy from lesion tissue showed diffuse neutrophilic infiltration in dermis along with caseous necrosis [Figure 2]. On clinicopathological correlation, we arrived at a final diagnosis of scrofuloderma.

The patient was prescribed anti-tubercular drug as per prevailing national guidelines and was started on intensive phase which included isoniazid (H) $75 \mathrm{mg}$, rifampicin (R) $150 \mathrm{mg}$, pyrazinamide (Z) $400 \mathrm{mg}$, and ethambutol (E) $275 \mathrm{mg}$ two tablets / day for two months. On follow up visit after two months, the patient showed significant clearing of lesions [Figure 3]. Thus, the correct diagnosis and treatment for a rare case like scrofuloderma was reinforced.

\author{
Corresponding Author: \\ Dr. Bhushan Madke, \\ Professor and Head, \\ Department of Dermatology, \\ Venereology \& Leprosy, \\ Jawaharlal Nehru Medical College, \\ Datta Meghe Institute of Medical \\ Sciences, Wardha, Maharashtra, India. \\ E-mail:drbhushan81@gmail.com
}

DOI: $10.14260 /$ jemds/2021/67

How to Cite This Article:

Rimmalapudi S, Morey AD, Madke B, et al. A rare case of tuberculosis cutis colliquative.J Evolution Med Dent Sci 2021;10(05):305307, DOI: 10.14260/jemds/2021/67

Submission 09-09-2020,

Peer Review 02-12-2020,

Acceptance 08-12-2020,

Published 01-02-2021.

Copyright (C) 2021 Shravya Rimmalapudi et al. This is an open access article distributed under Creative Commons Attribution License [Attribution 4.0 International (CC $B Y 4.0)]$ 


\begin{tabular}{|c|c|c|}
\hline Exogenous & Endogenous & Tuberculous \\
\hline Tuberculous chancre & $\begin{array}{l}\text { Contiguous spread: } \\
\text { Scrofuloderma }\end{array}$ & $\begin{array}{l}\text { Micropapular: } \\
\text { Lichen scrofulosorum }\end{array}$ \\
\hline Warty tuberculosis & $\begin{array}{l}\text { Auto-inoculation: } \\
\text { Orificial tuberculosis }\end{array}$ & $\begin{array}{l}\text { Papular: Papular or } \\
\text { papulonecrotic } \\
\text { tuberculid: }\end{array}$ \\
\hline Lupus vulgaris & $\begin{array}{l}\text { Haematogenous: } \\
\text { Miliary tuberculosis } \\
\text { Lupus vulgaris } \\
\text { Tuberculous gumma }\end{array}$ & $\begin{array}{l}\text { Nodular: Erythema nodosum } \\
\text { Erythema induratum }\end{array}$ \\
\hline \multicolumn{3}{|c|}{ Table 1. Classification of Cutaneous Tuberculosis } \\
\hline
\end{tabular}
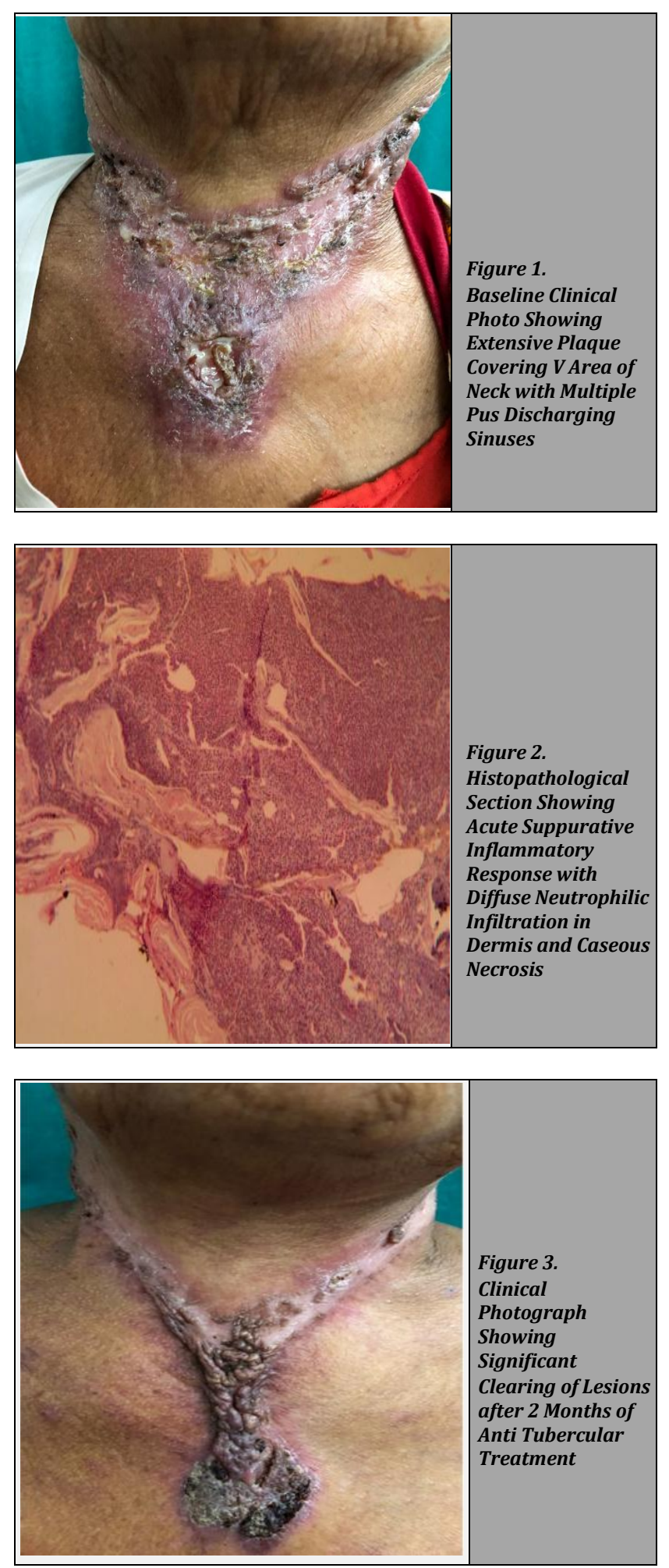

\section{DISCUSSION}

The average prevalence of all forms of tuberculosis in India is estimated to be 5.05 per thousand. ${ }^{4}$ Even though cutaneous TB is around $1.5 \%$ of all cases of TB, it is important for doctors to consider this infection when they face a suggestive clinical picture. $^{2}$ Cutaneous TB is an uncommon form of extrapulmonary $\mathrm{TB}$ and is difficult to distinguish and diagnose ${ }^{5}$ Approximately $95 \%$ of mycobacterial cervical infections in adults are caused by Mycobacterium Tuberculosis and the rest are caused by atypical mycobacterium whereas this trend is reversed in children. M. tuberculosis is an obligate aerobe and is transmitted from person to person via respiratory route. Silent dissemination occurs through lympho-haematogenous system to extra pulmonary sites. Finding bacilli in a cutaneous tuberculosis lesion is a challenge. ${ }^{6}$ Classification of cutaneous TB is given below (Table 1). During the middle ages, TB of the neck and lymph nodes was called "scrofula" which is a Latin word for brood sow. Scrofuloderma is the most common form of cutaneous TB in children and was due to milk contaminated with Mycobacterium bovis. ${ }^{3}$ But in current case, the patient is 65 years, and her son had a history of pulmonary TB, so we concluded that as a possible cause of infection. It develops as a direct extension from an underlying TB focus, for example a regional lymph node, an infected bone or joint to the overlying skin. The common site of involvement is the cervical region, with infected cervical lymph nodes breaking down into the skin. The lesions are firm, painless, subcutaneous nodules that gradually enlarge, suppurate and then form ulcers and sinus tracts with purulent, watery or caseous discharge making possible differential diagnosis of bacterial abscesses, tumour metastasis, histiocytosis, hidradenitis, actinomycosis, sporotrichosis, botryomycosis and nocardiosis which need to be excluded. 7 Typical ulcers show undermined violaceous edges and floor of granulation tissue. Histopathology shows extensive caseation necrosis and a tuberculoid granulomatous infiltrate on a background of granulation tissue. ${ }^{7}$ Chest x-rays are mandatory to rule out systemic TB. Serology tests mainly human immunodeficiency virus (HIV) test should be performed. Polymerase chain reaction (PCR) has low sensitivity but high specificity. Tuberculin sensitivity usually has low sensitivity. ${ }^{2}$ Cartridge- based nucleic acid amplification test (CB-NAAT) report of the discharge plays important role in diagnosis. In this case Mantoux test was positive and CBNAAT report of the pus detected Mycobacterium tuberculosis (MTB) of very low quantity with biopsy showing characteristic caseous necrosis confirming the diagnosis.

In the treatment of cutaneous TB, general measures should be taken first like treating the malnutrition, any associated illness, and also people in close contact with the patient should undergo testing for TB. Anti-TB treatment should be started as per World Health Organization (WHO) recommendation of therapy for extrapulmonary TB which consists of four drugs, isoniazid $(\mathrm{H})$, rifampicin $(\mathrm{R})$, pyrazinamide $(\mathrm{Z})$, and ethambutol (E) given for 2 months which is the intensive phase followed by rifampicin and isoniazid given for the next four months which is the continuation phase.

There are very few case-reports available on scrofuloderma. In one of the case reports, there were ulcers with drainage of pus on the face, the patient was treated with 
2 months of anti-tubercular drugs (intensive phase) and 20 days later the ulcers started to heal with no discharge present. ${ }^{2}$ In another case report, the lesions were on neck and patient was treated with 2 months of intensive phase and 4 months of continuation phase after which the skin lesions healed completely leaving behind scars. ${ }^{8}$ A number of articles on extrapulmonary and drug resistant tuberculosis by S.K. Sharma are available. ${ }^{9-11}$ Studies on different kind of skin lesions, dermatophytosis ${ }^{12-14}$ and treatment modalities ${ }^{15-17}$ were reviewed.

The patient in our case report showed dramatic improvement after 2 months of intensive phase which reinforces correct diagnosis of cutaneous TB.

Even though medical treatment is primary, surgery like electrosurgery, curettage along with electrodessication and cryosurgery can be considered as an adjunct therapy.

\section{CONCLUSIONS}

It is worth reporting this case due to its rare presentation and easy misdiagnosis. Hence, proper history, examination and investigations should be done for early diagnosis and treatment in order to achieve complete resolution along with awareness regarding various cutaneous TB. Regular follow up and patient's compliance also plays a crucial role in successful treatment. We also need to pay keen attention to the cause of cutaneous TB as it can enter through various routes. Hence, collaborative efforts at improving the housing facilities, decreasing overcrowding, enhancing the socioeconomic status, creating awareness about health and hygiene, and easy access of primary health care facilities to the general population in developing countries may help in the eradication of tuberculosis.

Financial or other competing interests: None.

Disclosure forms provided by the authors are available with the full text of this article at jemds.com.

\section{REFERENCES}

[1] Adigun R, Singh R. Tuberculosis. In: Stat Pearls. Treasure Island (FL): Stat Pearls Publishing. https://www.ncbi.nlm.nih.gov/books/NBK441916/

[2] Ganesan A, Kumar G. Scrofuloderma: a rare cutaneous manifestation of tuberculosis. J Indian Acad Oral Med Radiol 2017;29(3):223-6.

[3] Sandhu GK. Tuberculosis: current situation, challenges and overview of its control programs in India. J Glob Infect Dis 2011;3(2):143-50.
[4] Chakraborty AK. Epidemiology of tuberculosis: current status in India. Indian J Med Res 2004;120(4):248-76.

[5] Chen Q, Chen W, Hao F. Cutaneous tuberculosis: a great imitator. Clin Dermatol 2019;37(3):192-99.

[6] Santos JB, Figueiredo AR, Ferraz CE, et al. Cutaneous tuberculosis: diagnosis, histopathology and treatmentpart II. An Bras Dermatol 2014;89(4):545-55.

[7] Frankel A, Penrose C, Emer J. Cutaneous tuberculosis: a practical case report and review for the dermatologist. J Clin Aesthet Dermatol 2009;2(10):19-27.

[8] Haase 0, von Thomsen AJ, Zillikens D, et al. Recurrent abscesses of the neck: scrofuloderma. JAMA Dermatol 2014;150(8):909-10.

[9] Sharma SK, Chaubey J, Singh BK, et al. Drug resistance patterns among extra-pulmonary tuberculosis cases in a tertiary care centre in North India. Int J Tuberc Lung Dis 2017;21(10):1112-7.

[10] Sharma SK, Mohan A, Singh AD, et al. Impact of nicotine replacement therapy as an adjunct to anti-tuberculosis treatment and behaviour change counselling in newly diagnosed pulmonary tuberculosis patients: an openlabel, randomised controlled trial. Sci Rep 2018;8(1):8828.

[11] Sharma SK, Dheda K. What is new in the WHO consolidated guidelines on drug-resistant tuberculosis treatment? Indian J Med Res 2019;149(3):309-12.

[12] Begum J, Mir NA, Lingaraju MC, et al. Recent advances in the diagnosis of dermatophytosis. J Basic Microbiol 2020;60(4):293-303.

[13] Sahu PJ, Singh AL, Kulkarni S, et al. Study of oral tranexamic acid, topical tranexamic acid and modified Kligman's regimen in treatment of melasma. Journal of Cosmetic Dermatology 2020;19(6):1456-62.

[14] Gajbhiye V, Lamture Y. Minoxidil a youth elixir for eyebrow hypotrichosis. Journal of Clinical and Diagnostic Research 2020;14(2):PC01-3.

[15] Deshmukh S, Singh S, Jawade SA, et al. Treatment of genital warts with a combination of cryotherapy and $5 \%$ imiquimod. Journal of Clinical and Diagnostic Research 2020;14(2):WD01-3

[16] Kulkarni S, Sahu PJ, Patil A, et al. Neonatal pemphigus in a neonate of a mother suffering from pemphigus vulgaris- a case presentation. Journal of Clinical and Diagnostic Research 2020;14(1):WD1-3.

[17] Kute PK, Muddeshwar MG, Sonare AR. Pro-oxidant and anti-oxidant status in patients of psoriasis with relation to smoking and alcoholism. J Evolution Med Dent Sci 2019;8(34):2677-80. 